\title{
The course of alterations in ureteral jet dynamics following kidney transplantation: a prospective observational cohort study
}

\author{
(iD) Serdar Celik ${ }^{1}$ \\ (i) Türker Acar ${ }^{2}$ \\ (D) Cenk Simsek ${ }^{3}$ \\ (iD) Arda Yesilova ${ }^{1}$ \\ (iD) Erhan Tatar ${ }^{4}$ \\ (iD) Ibrahim Halil Bozkurt ${ }^{1}$ \\ (D) Yusuf Kadir Topcu ${ }^{1}$ \\ (iD) Ertuğrul Sefik ${ }^{1}$ \\ (iD) Ismail Basmaci \\ (iD) Bulent Gunlusoy ${ }^{1}$ \\ (iD) Tansu Degirmenci ${ }^{1}$ \\ (iD) Adam Uslu
}

\begin{abstract}
1. University of Health Sciences, Izmir Bozyaka Training and Research Hospital, Department of Urology, Izmir, Turkey. 2. University of Health Sciences, Izmir Bozyaka Training and Research Hospital, Department of Radiology, Izmir, Turkey. 3. University of Health Sciences, Izmir Bozyaka Training and Research Hospital, Department of General Surgery, Division of Transplantation, Izmir, Turkey. 4. University of Health Sciences, Izmir Bozyaka Training and Research Hospital, Department of Nephrology, Izmir, Turkey.
\end{abstract}

http://dx.doi.org/10.1590/1806-9282.66.2.153

\section{SUMMARY}

OBJECTIVES: To prospectively investigate the alterations and normal ranges of ureteral jet dynamics after double-J-stent (DJS) removal in patients who underwent renal transplantation $(R T x)$.

METHODS: Patients who underwent RTx were prospectively evaluated between November 2017 and June 2018. After RTx, Doppler ultrasonography (D-US) was performed on all patients after DJS removal. Renal artery resistive index (RA-Ri), renal pelvis anterior-posterior diameter (RP-APD), pelvicalyceal system dilation (PCSD), and ureteral jet flow dynamics (maximum and average velocity; JETmax and JETave) were measured by D-US. Also, patients' demographics, estimated glomerular filtration rate (eGFR) levels, and acute rejection were investigated in the study. Patients were assessed two different times by D-US, about 6 and 12 weeks after DJS removal, and the two different measurements were compared with the Wilcoxon test and Chi-square test.

RESULTS: A total of 25 patients were evaluated in the study. Nonobstructive PCSD rate (12\% vs $8 \%$ ), JETave (18.8 vs $12.9 \mathrm{~cm} / \mathrm{sec}$ ), and JETmax (29.2 vs $20 \mathrm{~cm} / \mathrm{sec}$ ) levels were significantly decreased (p values are 0.01, 0.010 and 0.014, respectively). In addition, monophasic and square pattern rates were significantly observed to increase over time $(p=0.035)$; however, ureteral jet patterns were correlated between the two different $D$-US measurements $(R=0.225, p=0.032)$.

CONCLUSION: After RTX, dilation rate and ureteral jet flow velocities were significantly decreased, and monophasic and square JETpattern rates were significantly increased over time. Ureteral jet dynamics can provide useful information about the follow-up of peristaltic activity in the pelvic-ureteric system.

KEYWORDS: Kidney transplantation. Urination/physiology. Urodynamics/physiology.

DATE OF SUBMISSION: 01-Aug-2019

DATE OF ACCEPTANCE: 01-Aug-2019

CORRESPONDING AUTHOR: Serdar Celik

Health Sciences University, Bozyaka Training and Research Hospital, Department of Urology and Dokuz Eylul University,

Institute of Oncology, Department of Basic Oncology, Izmir, Turkey, 35340

Tel: +90 5057019631

E-mail: serdarcelik84@hotmail.com 


\section{INTRODUCTION}

Chronic renal failure $(\mathrm{CRF})$ prevalence is in the range of $11-13 \%{ }^{1}$ After routine follow-up with or without hemodialysis (HD), the standard management of $\mathrm{CRF} / \mathrm{end}$-stage kidney disease (EKD) is renal transplantation (RTx). ${ }^{2}$ However, many complications can cause significant morbidity after RTx in these patients. ${ }^{3}$ Therefore, close follow-up with urine amount, ultrasonography (US), and estimated glomerular filtration rate (eGFR) or serum creatinine level is needed.

Doppler US (D-US), which is a non-invasive and easy examination method to assess ureteral jet phenomenon showing peristaltic activity in the pelvic-ureteric system, can be used for the evaluation of RTx patients. ${ }^{4}$ In the evaluation of the ureteral jet phenomenon with D-US, ureteral jet dynamics of maximum rate (JETmax), average rate (JETave), resistive index (JET-Ri), and wave form (JETpattern) of ureteral jet flow are measured in RTx patients. ${ }^{4}$ A study found that JETmax and JETave were significantly low and the monophasic JETpattern was more common (66.1\%) in RTx kidneys compared to healthy kidneys. ${ }^{5}$ However, the course of these alterations was not clear after RTx. Therefore, we aimed to prospectively investigate the alterations and normal ranges for ureteral jet dynamics over time after double $\mathrm{J}$ stent (DJS) removal in a patient cohort who underwent RTx.

\section{METHODS}

After ethical approval was obtained from the local committee and informed consent forms were obtained from patients, patients who underwent RTx due to CRF/EKD in our tertiary hospital between November 2017 and June 2018 were prospectively evaluated. Patients' demographics (age, gender, and body mass index (BMI)), HD time, and basal eGFR level of patients were noted before RTx. Also, donor type (cadaver/ live), RTx side (right/left iliac fossa), and operation time were noted. The Lich-Gregoir ureterovesical anastomosis technique was performed for all cases. Also, end-to-side anastomosis of donor-renal-artery to recipient external iliac artery or end-to-end anastomosis to recipient internal iliac artery was performed for arterial anastomosis. About four weeks after RTx, all DJS were removed with 17 fr flexible cystoscopy under local anesthesia. After DJS removal, the eGFR level and pelvicalyceal system dilation (PCSD) presence in the RTx kidney were also evaluated with renal US (R-US).
In the follow-up, two D-US examinations were performed to measure renal pelvis anterior-posterior diameter (RP-APD), renal artery resistive index (RA-Ri), and ureteral jet dynamics (JETmax, JETave, JET-Ri, and JETpattern) at different times.$^{6-9}$ First, D-US examination was performed about 6 weeks after DJS removal, and the second D-US examination was performed about 12 weeks after DJS removal. PCSD presence was also checked during the examinations by D-US, US, and magnetic resonance urography (MRU). D-US was performed by an experienced radiologist (TA) who performed blind examination using 3-5 MHz convex probe (Aplio 500; Toshiba Medical System Corporation, Tokyo, Japan) (Figure 1). Patients were placed in the supine position with full bladder after oral hydration with 500-750 ml water. All D-US data were measured with angle correction. During D-US measurements, the insonation of a renal artery and ureteral jet at a Doppler angle equal or above $60^{\circ}$ was strictly avoided. In addition, acute rejection presence was noted during the follow-up. For the determination of alterations in the ureteral jet dynamics, the D-US measurements were divided into two groups, i.e., first D-US examination and second D-US examination. Measurements were compared between the groups.

\section{Statistical analysis}

Statistical Package for Social Sciences version 20.0 (SPSS, Chicago, Ill) software program was used for data analysis. To compare the paired data from the D-US examinations, the Wilcoxon signed ranks test, Chi-square test, and Pearson R correlation analysis were used. Data are given as mean \pm SD. However, $\mathrm{p}$-values are given according to the medians. The statistical significance was defined as $p<0.05$.

\section{RESULTS}

In the study, a total of 31 patients were investigated. Six of them were excluded for various reasons (two patients had missing data, one patient did not have any ureteral jet observed, and three patients had a postrenal obstruction and underwent DJS placement after the first D-US removed).

For the 25 patients included, the mean age was $41.5 \pm 13.3$ (22-63) years, mean BMI was $23 \pm 3.9$ (17.5-33.8) kg/m², 18 were male, and 7 were female. Mean HD time was $41.9 \pm 41.1$ (0-144) months, and eGFR level was $12.6 \pm 6.1(5.3-27.8) \mathrm{ml} / \mathrm{min} / 1.73 \mathrm{~m}^{2}$ before RTx. 
TABLE 1. DEMOGRAPHIC DATA OF THE PATIENTS

\begin{tabular}{|c|c|c|}
\hline \multirow{2}{*}{\multicolumn{2}{|c|}{ Age (year), mean $\pm S D$ (min-max) }} & \multirow{3}{*}{$\begin{array}{l}\text { Patients }(n=25) \\
41.5 \pm 13.3(22-63) \\
7(28)\end{array}$} \\
\hline & & \\
\hline \multirow{2}{*}{ Gender, n (\%) } & Female & \\
\hline & Male & $18(72)$ \\
\hline \multicolumn{2}{|c|}{ BMI (kg/m2), mean \pm SD (min-max) } & $23 \pm 3.9(17.5-33.8)$ \\
\hline \multicolumn{2}{|c|}{ Preoperative eGFR (ml/min/1.73m2), mean \pm SD (min-max) } & $12.6 \pm 6.1(5.3-27.8)$ \\
\hline \multicolumn{2}{|c|}{ HD positivity, $n(\%)$} & $23(92)$ \\
\hline \multicolumn{2}{|c|}{ HD time (months), mean $\pm S D$ (min-max) } & $41.9 \pm 41.1(0-144)$ \\
\hline \multicolumn{2}{|c|}{ RTx operation time (minutes), mean \pm SD (min-max) } & $204.4 \pm 18.3(180-240)$ \\
\hline \multirow{2}{*}{ RTx side, $n(\%)$} & Right & $18(72)$ \\
\hline & Left & $7(28)$ \\
\hline \multirow{2}{*}{ Donor, n (\%) } & Cadaver & $14(56)$ \\
\hline & Live & $11(44)$ \\
\hline \multirow{3}{*}{ Acute Rejection, n (\%) } & Negative & $16(64)$ \\
\hline & Borderline changes & $4(16)$ \\
\hline & Positive & $5(20)$ \\
\hline \multicolumn{2}{|c|}{ eGFR after DJS removal (ml/min/1.73m2), mean $\pm S D$ (min-max) } & $58 \pm 13.3(20-77)$ \\
\hline
\end{tabular}

The types of donor were cadaver and live for 14 and 11 cases, respectively. The side of RTx was right and left iliac fossa for 18 and 7 patients, respectively. The mean RTx operation time was 204.4 \pm 18.3 (180-240) minutes. The mean eGFR level found was $58 \pm 13.3$ (20$77) \mathrm{ml} / \mathrm{min} / 1.73 \mathrm{~m}^{2}$ and $53.7 \pm 14.7(23-80) \mathrm{ml} / \mathrm{min} / 1.73 \mathrm{~m}^{2}$ for 6 and 12 weeks after DJS removal, respectively. Prednisolone and mycophenolate mofetil, or mycophenolic acid and everolimus, or tacrolimus were given as immunosuppressive and immunomodulatory drugs to all patients to protect against kidney rejection. Nevertheless, acute kidney rejection developed in five cases (T-cell-mediated rejection in three and antibody-mediated rejection in two patients), and they are still in follow-up.

The first D-US examination was performed about 6 weeks after DJS removal (mean time was $42.6 \pm 9.4$ days). Nonobstructive PCSD rate, RP-APD, RA-Ri, JET-Ri, JETave, JETmax, and JETpattern are presented in Table 2. Three patients had nonobstructive dilation (obstruction excluded by D-US, urine amount, creatinine level and MR-U), JETave, and JETmax were $18.8 \pm 12(7.1-58.1) \mathrm{cm} / \mathrm{s}$ and $29.2 \pm 18.7(8-85.6) \mathrm{cm} / \mathrm{s}$, respectively. Monophasic, square, and continuous patterns were present in $6(24 \%), 7(28 \%)$, and $7(28 \%)$ patients, respectively.

The second D-US examination was performed about 6 weeks after the first D-US evaluation (mean time was $42.6 \pm 16.8$ days). Nonobstructive PCSD rate, RP-APD, RA-Ri, and ureteral jet dynamics are also presented in Table 2. Two patients had nonob-

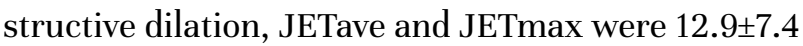

$(2.7-29.6) \mathrm{cm} / \mathrm{s}$ and $20 \pm 10.9(4.4-40.2) \mathrm{cm} / \mathrm{s}$, respectively. Monophasic, square, and continuous patterns were present in $9(36 \%), 8(32 \%)$, and $5(20 \%)$ patients, respectively. In the follow-up, all nonobstructive dilations had regressed by the six-month US evaluation.

The course of the alterations in the ureteral jet dynamics and the comparison of the results are presented in Table 2. In addition, the first and second D-US measurements of patients are shown in figure 2. Nonobstructive PCSD rate, JETave, and JETmax levels were significantly decreased (p-values are 0.01 , 0.010 , and 0.014, respectively). In addition, monophasic $(24 \%$ vs $36 \%)$, biphasic ( $12 \%$ vs $12 \%)$, triphasic $(8 \%$ vs $0 \%$ ), polyphasic (0\% vs $0 \%$ ), square ( $28 \%$ vs $32 \%)$, and continuous ( $28 \%$ vs $20 \%$ ) patterns significantly differed over time ( $\mathrm{p}=0.035)$. Also, monophasic and square pattern rates were significantly observed to increase over time ( $\mathrm{p}=0.035)$; however, ureteral jet patterns were correlated between the two different D-US measurements $(\mathrm{R}=0.225, \mathrm{p}=0.032)$.

\section{DISCUSSION}

Ureteral jet dynamics measured by D-US were recently evaluated for upper urinary tract stone disease to predict ureteral obstruction and stone formation. ${ }^{6,710,11}$ However, only a few studies have been reported so far about ureteral jet dynamics in RTx patients. A study reported that ureteral jets can be assessed noninvasively and easily using D-US for RTx kidneys. ${ }^{4}$ Therefore, D-US imaging of the ureteral jet dynamics can be used to follow-up or exclude ureteral 
obstruction in RTx kidneys. ${ }^{4}$ In a recent study, the velocity and frequency of ureteral jets were found to be significantly lower in RTx kidneys compared with healthy kidneys. ${ }^{5}$ In the literature, peak (JETmax) and mean (JETave) jet flow velocities varied from 16 to 150 $\mathrm{cm} / \mathrm{sec}$ for healthy kidneys. ${ }^{8,12,13}$ In this study, JETave and JETmax were $18.8 \pm 12(7.1-58.1) \mathrm{cm} / \mathrm{s}$ and $29.2 \pm 18.7$ $(8-85.6) \mathrm{cm} / \mathrm{s}$ in the first D-US; and $12.9 \pm 7.4(2.7-29.6)$ $\mathrm{cm} / \mathrm{s}$ and $20 \pm 10.9(4.4-40.2) \mathrm{cm} / \mathrm{s}$ in the second D-US examination, respectively. Although the ureteral jet frequency is a part of ureteral jet dynamics, we did not measure it in our RTx patients. Documenting ureteral jet frequency requires at least 30 minutes of D-US examination. ${ }^{12}$ However, D-US was evaluated in about 5-10 minutes in most studies. ${ }^{10,11,14,15}$ Therefore, we did not measure ureteral jet frequency because of the 10-minute continuous rapid examination.

JETpattern distribution rates differ from healthy native kidneys and RTx kidneys. In RTx kidneys, JETpatterns are present as $66.1 \%, 23.2 \%, 3.6 \%, 0 \%, 5.4 \%$, and $1.8 \%$ for monophasic, biphasic, triphasic, polyphasic, square and continuous patterns, respectively. ${ }^{5}$ The monophasic wave pattern is more common in RTx kidneys (66.1\%) than in healthy kidneys $(2.6 \%) .{ }^{5}$ In our

\section{FIGURE 1. DATA MEASURED IN D-US EXAMINATION.}

A) Renal pelvis anterior-posterior diameter (RP-APD); B) Ureteral jet dynamics as JETmax, JETave, and JETpattern.

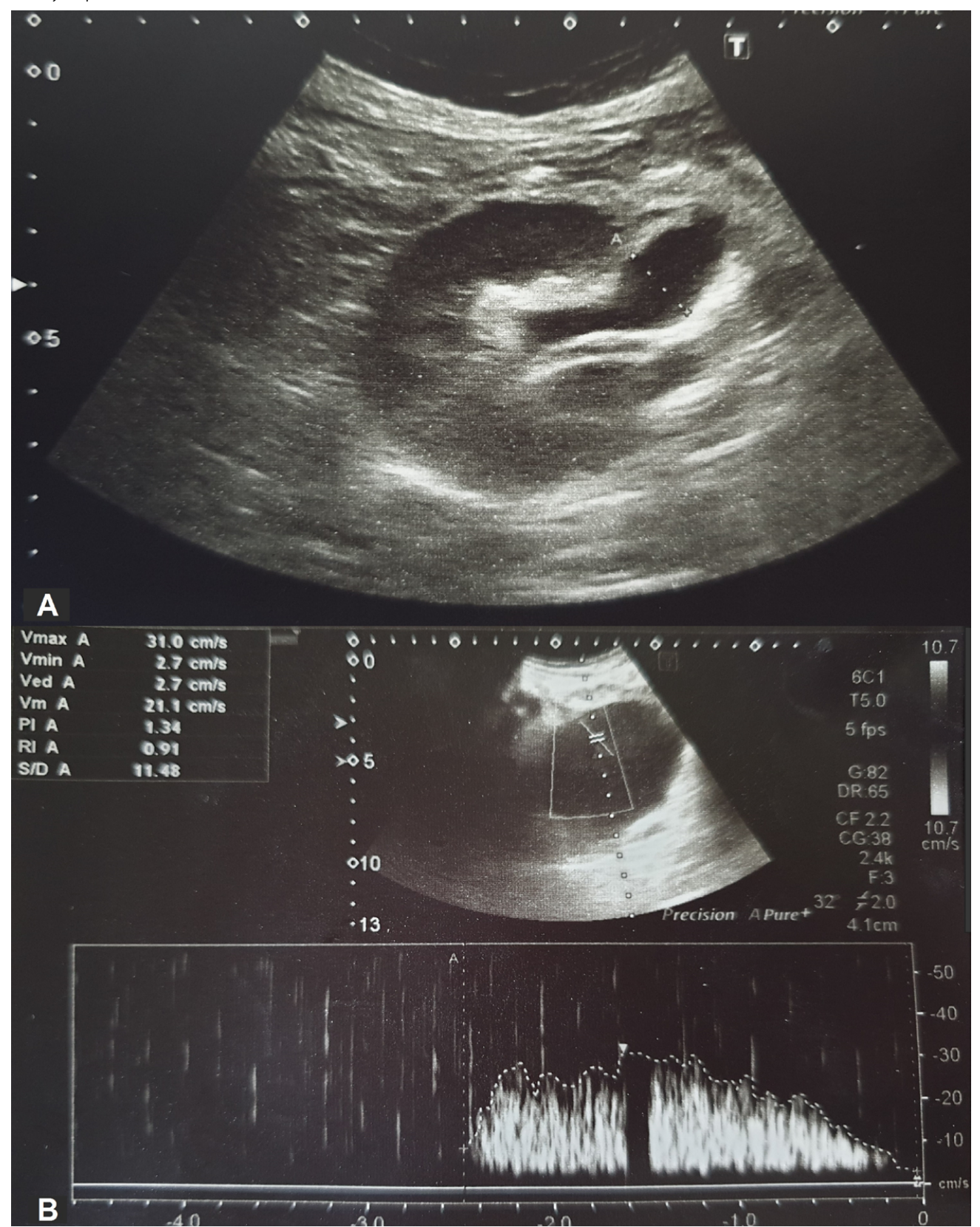


series, monophasic, square, and continuous patterns were $24 \%, 28 \%$, and $28 \%$ during the first D-US evaluation, and $36 \%, 32 \%$, and $20 \%$ during the second D-US evaluation, respectively.

When we evaluated the course of the alterations in ureteral jet dynamics and comparison results, nonobstructive PCSD presence (3 vs. 2, p=0.01), mean JETave (18.8 vs. $12.9, \mathrm{p}=0.010$ ), and mean JETmax (29.2 vs. $20, p=0.014$ ) levels significantly decreased over time.
In addition, monophasic and square JETpattern rates were observed to increase over time significantly; however, ureteral jet patterns were correlated between the two different D-US measurements ( $\mathrm{R}=0.225$, $\mathrm{p}=0.032)$.

In light of all results, ureteral jet flow rates normally decrease after RTx. However, the most important finding of the study is that, during the second D-US examination, these flow rates also decrease further than the levels at the first D-US examination

FIGURE 2. IMAGING DATA OF FIRST AND SECOND D-US EXAMINATIONS IN A PATIENT

A) In the first examination, the patient had $6.5 \mathrm{~mm}$ renal pelvis anterior-posterior diameter (RP-APD); B) 0.78 renal artery resistive index (RA-Ri); C) There were $34.5 \mathrm{~cm} / \mathrm{s} \mathrm{JETmax,} 19.4 \mathrm{~cm} / \mathrm{s}$ JETave, and biphasic JETpattern in the evaluation of ureteral jet dynamics; D) In the second examination, the patient had 5mm RP-APD; E) 0.88 RA-Ri; F) There were $17.1 \mathrm{~cm} / \mathrm{s} \mathrm{JETmax,}$ $11.4 \mathrm{~cm} / \mathrm{s} \mathrm{JETave,} \mathrm{and} \mathrm{continuous} \mathrm{JETpattern} \mathrm{in} \mathrm{the} \mathrm{patient} \mathrm{as} \mathrm{ureteral} \mathrm{jet} \mathrm{dynamics.}$

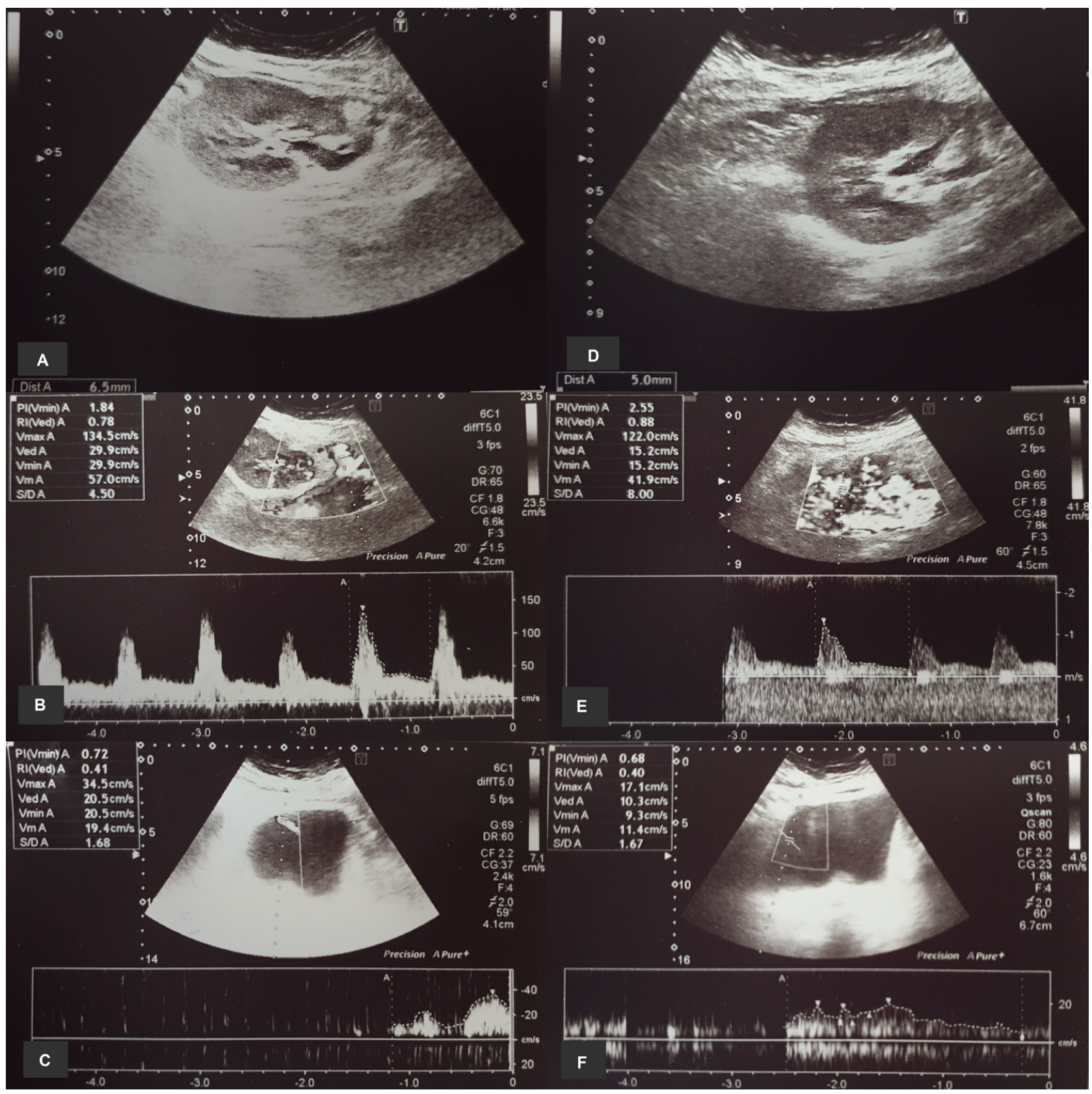


TABLE 2. D-US DATA AND COMPARISON OF THE RESULTS BETWEEN 6 WEEKS AND 12 WEEKS AFTER DJS REMOVAL IN PATIENTS WHO UNDERWENT RTX

\begin{tabular}{|c|c|c|c|c|}
\hline & & $\begin{array}{l}\text { First D-US examination } \\
6 \text { weeks after DJS removal }\end{array}$ & $\begin{array}{l}\text { Second D-US examination } \\
12 \text { weeks after DJS removal }\end{array}$ & $\mathrm{p}$ \\
\hline \multicolumn{2}{|c|}{ Nonobstructive PCSD presence, n (\%) } & $3(12)$ & $2(8)$ & $0.01^{\#}$ \\
\hline \multicolumn{2}{|c|}{ RP-APD (mm), mean $\pm S D(\min -\max )$} & $6.8 \pm 4.3(2.8-23)$ & $6.4 \pm 3.2(3.2-14.7)$ & 0.509 \\
\hline \multicolumn{2}{|c|}{ RA-Ri, mean $\pm S D($ min-max $)$} & $0.76 \pm 0.08(0.61-0.92)$ & $0.76 \pm 0.08(0.61-0.88)$ & 0.948 \\
\hline \multicolumn{2}{|c|}{ 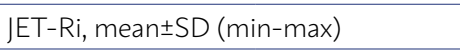 } & $0.66 \pm 0.18(0.19-0.92)$ & $0.66 \pm 0.23(0.26-1.02)$ & 0.765 \\
\hline \multicolumn{2}{|c|}{ JETave (cm/s), mean \pm SD (min-max) } & $18.8 \pm 12(7.1-58.1)$ & $12.9 \pm 7.4(2.7-29.6)$ & 0.01 \\
\hline \multicolumn{2}{|c|}{ JETmax (cm/s), mean $\pm S D(\min -\max )$} & $29.2 \pm 18.7(8-85.6)$ & $20 \pm 10.9(4.4-40.2)$ & 0.014 \\
\hline \multirow{6}{*}{ JETpattern, n (\%) } & Monophasic & $6(24)$ & $9(36)$ & \multirow{6}{*}{$0.035^{\#}$} \\
\hline & Biphasic & $3(12)$ & $3(12)$ & \\
\hline & Triphasic & $2(8)$ & $O(0)$ & \\
\hline & Polyphasic & $\mathrm{O}(0)$ & $O(0)$ & \\
\hline & Square & $7(28)$ & $8(32)$ & \\
\hline & Continuous & $7(28)$ & $5(20)$ & \\
\hline
\end{tabular}

Abbreviations: $P C S D=$ pelvicaliceal system dilation, $\mathrm{RP}-\mathrm{APD}=$ renal pelvis anterior-posterior diameter, $\mathrm{RA}-\mathrm{Ri}=$ renal arterial resistive index, JET-Ri $=$ resistive index of ureteral jet flow, JETave = average ureteral jet flow, JETmax = maximum ureteral jet flow, JETpattern = ureteral jet flow wave form pattern. $\mathrm{P}$ was calculated by Wilcoxon signed ranks test between paired data. \#Chi-square analysis. ${ }^{*}$ Pearson'R correlation analysis

for RTx kidneys. Therefore, D-US evaluation of ureteral jet dynamics performed at regular intervals and JETave, JETmax, and JETpattern measured after DJS removal may provide important data about reno-ureteral physiology. Our study continues, and measurements will be received at regular intervals. At the end of the study, all of these data will provide normal ranges for reno-ureteral unit dynamics in healthy RTx kidney, similarly to this preliminary paper. After receiving and knowing the normal ranges for the dynamics, alterations can be investigated and interpreted for complicated RTx patients compared to healthy RTx patients.

There are some limitations to our study. The study included a small number of patients and did not include measurement of ureteral jet frequency. Moreover, the cohort did not include any control group. However, it included short-term preliminary results of an observational cohort, and it is part of an ongoing study with a large cohort investigating all D-US measurements.

\section{CONCLUSIONS}

In conclusion, nonobstructive PCSD rate and ureteral jet flow velocities significantly decreased over time after RTx and DJS removal. Also, monophasic and square JETpattern rates were observed to increase over time significantly. Ureteral jet dynamics measured by D-US can provide useful information about the follow-up of peristaltic activity in the pelvic-ureteric system in relation to the health of RTx kidneys after DJS removal.

\section{Acknowledgments:}

None.

\section{Sources of Funding:}

None.

\section{Conflict of interest:}

The authors declare there are no conflicts of interest.

\section{Authors contributions:}

Concept: Serdar Celik, Türker Acar, Cenk Simsek; Design: Serdar Celik, Türker Acar, Cenk Simsek, Adam Uslu; Data Collection: Serdar Celik, Türker Acar, Cenk Simsek, Erhan Tatar, Arda Yesilova; Data Processing: Serdar Celik, Arda Yesilova, Ibrahim Halil Bozkurt, Yusuf Kadir Topcu, Ertuğrul Sefik, Ismail Basmaci; Data Analysis and Interpretation: Serdar Celik, Erhan Tatar, Ibrahim Halil Bozkurt, Bulent Gunlusoy, Tansu Degirmenci; Literature Research: Serdar Celik, Türker Acar, Cenk Simsek, Arda Yesilova; Writing: Serdar Celik. 


\section{RESUMO}

OBJETIVOS: Investigar prospectivamente as alterações e as variações normais da dinâmica do jato ureteral após a remoção do J-stent duplo (DJS) em pacientes submetidos a transplante renal (RTX).

MÉTODOS: Pacientes submetidos a RTx foram avaliados prospectivamente entre novembro de 2017 e junho de 2018. Após o RTx, o D-US foi realizado em todos os pacientes após a remoção do DJS. Índice de resistência da artéria renal (RA-Ri), diâmetro ântero-posterior da pelve renal (AP-DPR), dilatação do sistema pelvicaliceal (PCSD) e dinâmica do jato ureteral (velocidade máxima e média; JETmax e JETave) foram medidos por D-US. Além disso, a demografia dos pacientes, os níveis estimados de taxa de filtração glomerular (eGFR) e a rejeição aguda foram investigados no estudo. Os pacientes foram avaliados em dois momentos diferentes pelo D-US, cerca de 6 e 12 semanas após a remoção do DJS, e as duas medidas diferentes foram comparadas com o teste de Wilcoxon e o teste do qui-quadrado.

RESULTADOS: Um total de 25 pacientes foi avaliado no estudo. Taxa de PCSD não obstrutiva (12\% vs. 8\%), JETave (18,8 vs. $12,9 \mathrm{~cm} / \mathrm{seg}) \mathrm{e}$ JETmax (29,2 vs. $20 \mathrm{~cm} / \mathrm{seg}$ ), os níveis foram significativamente diminuídos (valores de p são 0,01, 0,010 e 0,014, respectivamente). Além disso, as taxas de padrão monofásico e quadrado foram significativamente observadas para aumentar ao longo do tempo ( $p=0,035)$; no entanto, padrões de jato ureteral foram correlacionados entre as duas diferentes medidas D-US $(R=0,225, p=0,032)$.

CONCLUSÃo: Após o RTx, a velocidade de dilatação e as velocidades de fluxo do jato ureteral foram significativamente diminuídas e as taxas de JET padrão monofásico e quadrado foram significativamente aumentadas ao longo do tempo. A dinâmica do jato ureteral pode fornecer informações úteis sobre o acompanhamento da atividade peristáltica no sistema pélvico-ureteral.

PALAVRAS-CHAVE: Transplante de rim. Micção/fisiologia. Urodinâmica/fisiologia.

\section{REFERENCES}

1. Hill NR, Fatoba ST, Oke JL, Hirst JA, O'Callaghan CA, Lasserson DS, et al. Global prevalence of chronic kidney disease: a systematic review and meta-analysis. PLoS One. 2016;11(7):e0158765.

2. Breda A, Budde K, Figueiredo A, Lledó García E, Olsburgh |, Regele H, et al. European Association of Urology guidelines on renal transplantation. 2018. [cited 2019 Sep 3]. Available from: http://uroweb.org/guideline/ renal-transplantation/

3. Bhagat VJ, Gordon RL, Osorio RW, LaBerge JM, Kerlan RK Jr, Melzer JS, et al. Ureteral obstructions and leaks after renal transplantation: outcome of percutaneous antegrade ureteral stent placement in 44 patients. Radiology. 1998;209(1):159-67.

4. Wiesner W, Wedegaertner U, Stoffel F, Sonnet S, Bongartz G, Steinbrich W. Autonomous pelvi-ureteric peristalsis in renal transplants confirmed by color Doppler mapping of the jet phenomenon. Eur Radiol. 2001;11(3):525-6.

5. Leung $V Y$, Metreweli $C$. Ureteric jet in renal transplantation patient. Ultrasound Med Biol. 2002;28(7):885-8.

6. Celik S, Altay C, Bozkurt O, Uz G, Ongun S, Demir O, et al. Association between ureteral jet dynamics and nonobstructive kidney stones: a prospective-controlled study. Urology. 2014;84(5):1016-20.

7. Celik S, Bozkurt O, Altay C, Celebi Celik F, Uz G, Soylu A, et al. Evaluation of ureteral jet dynamics in pediatric kidney stone formers: a cross-sectional study. J Pediatr Urol. 2016;12(6):381.
8. Leung VY, Chu WC, Yeung CK, Metreweli C. Doppler waveforms of the ureteric jet: an overview and implications for the presence of a functional sphincter at the vesicoureteric junction. Pediatr Radiol. 2007;37(5):417-25.

9. Leung VY, Metreweli C, Yeung CK. The ureteric jet doppler waveform as an indicator of vesicoureteric sphincter function in adults and children. An observational study. Ultrasound Med Biol. 2002;28(7):865-72.

10. Jandaghi AB, Falahatkar S, Alizadeh A, Kanafi AR, Pourghorban R, Shekarchi $B$, et al. Assessment of ureterovesical jet dynamics in obstructed ureter by urinary stone with color Doppler and duplex Doppler examinations. Urolithiasis. 2013;41(2):159-63.

11. Ciftci H, Cece H, Dusak A, Savas M, Verit A, Yeni E. Study of the ureterovesical jet flow by means of dupplex Doppler ultrasonography in patients with residual ureteral stone after extracorporeal shock wave lithotripsy. Urol Res. 2010;38(1):47-50.

12. Cox IH, Erickson SI, Foley WD, Dewire DM. Ureteric jets: evaluation of normal flow dynamics with color Doppler sonography. AJR Am J Roentgenol. 1992;158(5):1051-5.

13. Matsuda T, Saitoh M. Detection of the urine jet phenomenon using Doppler color flow mapping. Int J Urol. 1995;2(4):232-4.

14. Asrat T, Roossin MC, Miller El. Ultrasonographic detection of ureteral jets in normal pregnancy. Am J Obstet Gynecol. 1998;178(6):1194-8.

15. Burke BJ, Washowich TL. Ureteral jets in normal second- and third-trimester pregnancy. J Clin Ultrasound. 1998;26(9):423-6. 